\begin{tabular}{|c|c|c|c|}
\hline \multirow{2}{*}{ Researeh Studies } & \multicolumn{2}{|c|}{ R\&S - RESEARCH STUDIES ANATOLIA JOURNAL } & \multirow{2}{*}{$\begin{array}{l}5 \\
\pm=-1\end{array}$} \\
\hline & www.dergipark.gov.tr/rs & Vol: 1, Issue: 2, pp. 352-357 & \\
\hline
\end{tabular}

Akbulut, M. U. F. (2018). “5302 Sayılı Yasanın Yerelleşme Bağlamında Değerlendirilmesi”, R\&S - Research Studies Anatolia Journal, Vol:1, Issue:2; pp: 352-357

\begin{tabular}{ll}
\hline \hline $\begin{array}{l}\text { Anahtar Kelimeler: Yerelleşme, İl Özel İdaresi, 5302 } \\
\text { Sayılı Kanun }\end{array}$ & $\begin{array}{l}\text { Keywords: Localization, Special Provincial } \\
\text { Administration, Law No. 5302 }\end{array}$ \\
\hline \hline
\end{tabular}

Makale Türü: Araştırma Makalesi

\title{
5302 SAYILI YASANIN YERELLEŞME BAĞLAMINDA DEĞERLENDİRİLMESİ
} Evaluation in the Context of Localization Law NO 5302

\section{Mahmut Umut Ferman AKBULUT}

Yüksek Lisans Mezunu, Selçuk Üniversitesi, Sosyal Bilimler Enstitüsü, Kamu Yönetimi ABD, umutferman6106@gmail.com Konya/Türkiye

\begin{tabular}{|c|c|}
\hline $\begin{array}{c}\text { Makale Geliş Tarihi } \\
\text { 03.07.2018 }\end{array}$ & $\begin{array}{c}\text { Yayınlanma Tarihi } \\
\text { 30.07.2018 }\end{array}$ \\
\hline ÖZ & ABSTRACT \\
\hline 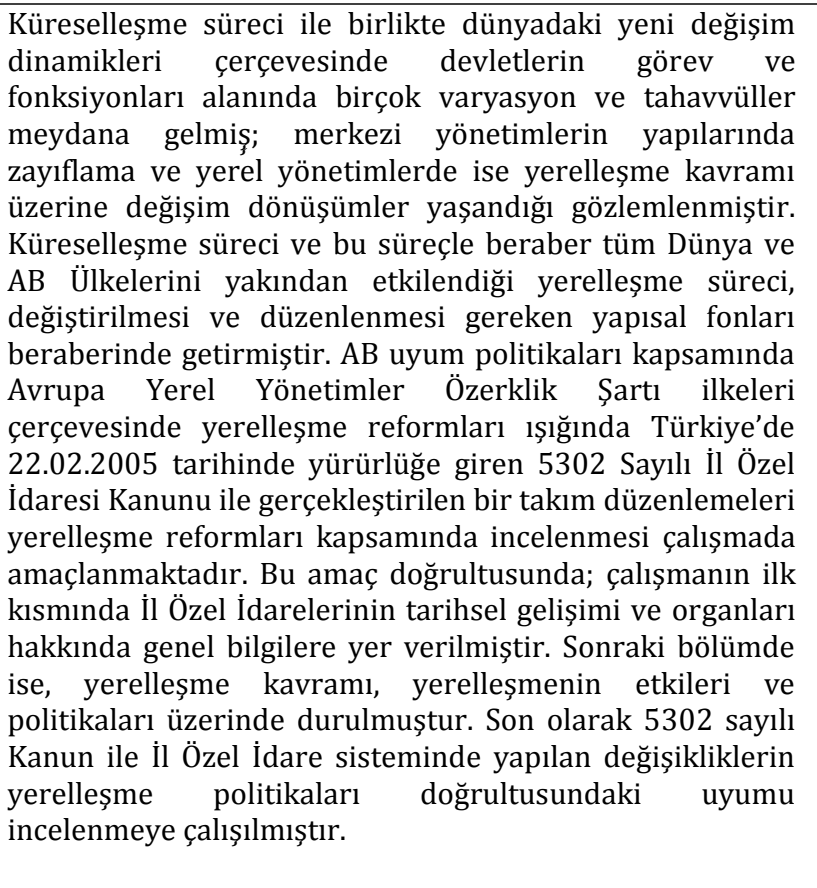 & $\begin{array}{l}\text { Along with the globalization process, there have been } \\
\text { many changes and transformations in the field of functions } \\
\text { and duties of states in the framework of the new dynamics } \\
\text { of change in the world. It has been observed that there has } \\
\text { been a change in the structure of central administrations } \\
\text { and a change in localization in local administrations. The } \\
\text { process of globalization and the process of localization, } \\
\text { which is closely influenced by the whole World and EU } \\
\text { Countries, brought together the structural funds that need } \\
\text { to be changed and regulated. A number of arrangements } \\
\text { made with the EU cohesion policy under the European } \\
\text { Local Self-Government Charter in the light of } \\
\text { decentralization reforms within the framework of } \\
\text { principles in Turkey on } 22.02 .2005 \text { enacted } 5302 \text { No. of } \\
\text { Special Provincial Administration Law is aimed to study } \\
\text { the scope of decentralization reforms. In the first part of } \\
\text { the work, general information about the historical } \\
\text { development and organs of Special Provincial } \\
\text { Administrations is given. In the next section, the concept of } \\
\text { localization, the effects of localization and policies are } \\
\text { emphasized. Lastly, Law No. } 5302 \text { tried to examine the } \\
\text { harmonization of the changes made in the Special } \\
\text { Provincial Administration system in line with localization } \\
\text { policies. }\end{array}$ \\
\hline
\end{tabular}

\section{GİRiş}

Dünyada genelinde yaşanılan hızlı değişim ve dönüşümlerle birlikte dünya ülkeleri, küreselleşmeyi ve yerelleşme süreçlerini birlikte yaşamakta, ülkeler siyasal ve ekonomik yönden birleşmeye doğru adım atarken yerel yönetimler de gittikçe önem kazanmaktadır. Özellikle toplumsal, siyasal ve ekonomi boyutunda meydana gelen gelişmeler, bu gelişmelerle birlikte ortaya çıkan içsel ve dışsal baskıların altında olan kurumları da değişime ve gelişime zorlamaktadır. Yönetimin yeniden şekillendirilmesi çalışmaları içerisinde yer alan ve gitgide önem kazanan yerel yönetimlerin, anayasalarda belirtildiği ve uluslararası anlaşmaların öngördükleri biçimde yapılandırılmasını sağlamak üzere merkezi ve yerel yönetimler arasındaki görev ve yetki paylaşımının yeniden düzenlenmesi ve bu paylaşım çerçevesinin iyi çizilmesi gerektiği ortaya çıkmıștır (Genç ve Barış, 2015: 108). Avrupa Birliğine uyum süreci doğrultusunda Türkiye'de 2000'li yıllardan itibaren kamusal hizmetlerin hemen hemen her alanında yeniden yapılandırmayı öngören bir "reform" süreci yaşanmaktadır. Yeniden yapılanma ya da uyum süreci olarak tanımlanan bu reformlar da özellikle küresel değişime ayak uyduramadığı savından hareketle devlet kurumları üzerinde yoğunlaşmaktadır(Yılmaz, 2010: 184; Akarçay, 2009: 51). 
Devletin yeniden yapılandırılmasına ilişkin reform programları çerçevesinde yapılan değişikliklerin, özellikle yerel yönetimler reformu olarak adlandırılan bir dizi yasalarla yerellik anlayışı çerçevesinde yerelleșme politikaları yönünde değişim yaşanmaktadır (Günal, vd: 2014: 68). Bu değișim kapsamında çalıșmada Türkiye'de İl Özel İdareleri ile ilgili gerçekleștirilen en son reform çalışması olan 5302 Sayılı İl Özel İdaresi Kanunu ve bu Kanunda gerçekleştiren yeniliklerin yerelleşme politikalarıyla ve Türkiye'nin $\mathrm{AB}$ ile müzakere yürüten ülke konumunda olması da dikkate alınarak, Avrupa Yerel Yönetimler Özerklik Sartları'na uygunluğu dikkate alınarak incelenecektir.

\section{2. İL ÖZEL IDARESI}

İl Özel İdarelerinin tarihsel sürecine bakıldı̆̆ı zaman 150 yıllık bir geçmişe sahip olduğu gözlenmektedir. 1864 tarihinde oluşturulan Vilayet Nizam- namesiyle birlikte illerin kuruluş süreci genel ve özel yönetim biçimi şeklinde varlığına başlamış ve bu yönetim biçimlerinden sadece birisi İl Özel İdareleri adıyla faaliyetlerine devam edebilmiş ve 1876 tarihli Kanuni Esasi ile özerk bir yerel yönetim idaresi haline gelmiştir. 1913 tarihli Umumiye-i Vilayet Kanun-u Muvakkat ile yetkili bir konuma ulaşan İl Özel İdareleri, 26.05. 1987 tarih ve 3360 sayılı Kanun ile mevcudiyetine devam etmiștir (Demirel, 2014: 174). Fakat Türkiye'de Anayasaların dahi çoğu kez yeniden düzenlendiği ve tebdil edildiği dönemlerde neredeyse fazla değişime uğramayıp çok az değișimle beraber 2000'li yıllara kadar ulaşan Umumiye-i Vilayet Kanun-u Muvakkat geçici Kanun'u beklentileri karşılayamaz düzeyine gelmesinden ötürü yeni “íl Özel İdaresi Kanunu'na olan ihtiyaç sürekli gündemdeki önemini korur hale gelmişti. Bu gelişmeler ışığında 2005 yılında Köy Hizmetlerinin varlığı son bulmuş İl Özel İdarelerinin yeniden düzenlemesi sürecine hız verilmiş ve 4 Mart 2005 tarihinde ilan edilen 5302 sayılı İl Özel İdareleri Yasası Resmi Gazete' de yayımlanarak yürürlüğe girmiștir (Koçak ve Kavsara, 2012: 65).

İl özel idarelerinin üç organı bulunmaktadır. Bunlar İl Genel Meclisi, İl Encümeni ve Validir. Bunlardan İl Genel Meclisi, İl Özel İdarelerinin temel karar organı, İl Encümeni yürütme organı, Vali ise, İl Özel İdaresi tüzel kişiliğinin başı ve yürütme organıdır( Çetin, 2009: 252).

\section{1. İl Genel Meclisi}

Kanunda İl Genel Meclisi, İl Özel İdaresinin karar organıdır ve ilgili kanunda gösterilen esas ve usullere göre ildeki seçmenler tarafından seçilmiş üyelerden oluşur (Md. 9). 5302 Sayılı kanun ile İl Genel Meclisi görev ve fonksiyonlarına değinecek olursak. Bunlar; stratejik planı kabul etmek, İl Özel İdaresi faaliyetleri ve personelin performans ölçütlerini kabul etmek, norm kadro çerçevesinde İl Özel İdaresinin ve bağlı kuruluşların kadrolarının ihdas, iptal ve değiştirilmesine karar vermek, meclis başkanı seçmek, ihdas komisyonu üyelerini seçmek, yurt içindeki ve yurt dışındaki mahalli idareler ile işbirliği yapılmasına karar vermek, olarak sıralanabilir (Koçak ve Kavsara, 2012: 65).

5302 Sayılı Kanunun 11. Maddesinde alınan karara karşı, İl Genel Meclisi, seçim sonuçlarının açıklandığı günün ardından beşinci gün toplanacak ve kendi üyeleri içerisinden gizli oyla, ilk iki yıllık zamanı kapsayacak șekilde meclis başkanını seçecektir. Böylece, Avrupa Yerel Yönetimler Özerklik 3. maddesinde öngörülen, "yerel yönetimlerin meclis üyelerinin seçimle gelmesi" ilkesi sağlanmış olacaktır (Sobacı, 2005: 40).

\section{2. İl Encümeni}

5302 sayılı yeni İl Özel İdaresi Kanunu'nun 25. maddesine göre “İl Encümeni Vali’nin başkanlığında, İl Genel Meclisinin her yll kendi üyeleri arasından bir yıl için gizli oyla seçeceği beş üye ile biri mali hizmetler birim amiri olmak üzere valinin her yll birim amirleri arasından seçeceği beş üyeden oluşur." (Md. 25). 5302 sayılı İl Özel İdaresi Kanunu'nun 26. Maddesi İl Encümeninin görev ve yetkilerini düzenlemektedir. Bu maddeye göre İl Encümeninin görev ve yetkileri şunlardır:

a) Stratejik plân ve yıllık çalışma programı ile bütçe ve kesin hesabı inceleyip İl Genel Meclisine görüş bildirmek.

b) Yıllık çalışma programına alınan işlerle ilgili kamulaștırma kararlarını almak ve uygulamak.

c) Öngörülmeyen giderler ödeneğinin harcama yerlerini belirlemek.

d) Bütçede fonksiyonel sınıflandırmanın ikinci düzeyleri arasında aktarma yapmak.

e) Kanunlarda öngörülen cezaları vermek.

f) Vergi, resim ve harçlar dışında kalan ve miktarı beş milyar Türk Lirasına kadar olan ihtilafların sulhen halline karar vermek. 
g) Taşınmaz mal satımına, trampa edilmesine ve tahsisine ilişkin kararları uygulamak, süresi üç yılı geçmemek üzere kiralanmasına karar vermek.

h) Belediye sınırları dışındaki umuma açık yerlerin açılış ve kapanış saatlerini belirlemek.

i) Vali tarafından havale edilen konularda görüş bildirmek.

j) Kanunlarla verilen diğer görevleri yapmak (Md. 26).

5302 sayılı kanunun 25. Maddesiyle İl Encümeninde atanmış üyelere de yer verilmiştir. Bu kanunla beraber İl Encümeninde seçilmiş ve atanmış üyeler yer almaktadır. Bu bağlamda il Encümeni yapısıyla alakalı önceki kanundaki düzenlemenin daha demokratik bir yapı getirdiği söylenebilir (Dal, 2016: 77).

\subsection{Vali}

İçişleri Bakanı'nın önerisi, Bakanlar Kurulu'nun kararı ve Cumhurbaşkanı'nın onanıyla atanan Vali, Devlet'in Hükümetin ve ayrı ayrı her bakanın temsilcisidir. Merkezi yönetimin ildeki bası ve temsilcisidir. Vali, İl Özel İdaresinin bası ve tüzel kişiliğinin temsilcisidir. Vali konumu acısından ikili göreve sahiptir. Vali, ilin yönetiminden en üst düzeyde sorumlu olduğu gibi aynı zamanda da yerel yönetim birimi olan İl Özel İdaresinin organlarından birisidir. Ayrıca valinin bu ikili görevi devlet ve milli irade arasında koordinasyonu da sağlamak açısından faydalıdır (Bayrakçı, 2011: 59). 5302 sayılı İl Özel İdaresi Kanunu'nun 30. Maddesi Vali'nin görev ve yetkilerini düzenlemektedir. Bu maddeye göre Vali'nin görev ve yetkileri şunlardır:

a) İl Özel İdaresi teşkilâtının en üst amiri olarak İl Özel İdaresi teşkilâtını sevk ve idare etmek, İl Özel İdaresinin hak ve menfaatlerini korumak.

b) İl Özel İdaresini stratejik plâna uygun olarak yönetmek, İl Özel İdaresinin kurumsal stratejilerini oluşturmak, bu stratejilere uygun olarak bütçeyi, İl Özel İdaresi faaliyetlerinin ve personelinin performans ölçütlerini hazırlamak ve uygulamak, izlemek ve değerlendirmek, bunlarla ilgili raporları meclise sunmak.

c) İl Özel İdaresini devlet dairelerinde ve törenlerde, davacı veya davalı olarak da yargı yerlerinde temsil etmek veya vekil tayin etmek.

d) İl Encümenine başkanlık etmek.

e) İl Özel İdaresinin taşınır ve taşınmaz mallarını idare etmek.

f) İl Özel İdaresinin gelir ve alacaklarını takip ve tahsil etmek.

g) Yetkili organların kararını almak şartıyla sözleşme yapmak.

h) İl Genel Meclisi ve Encümen kararlarını uygulamak.

i) Bütçeyi uygulamak, bütçede meclis ve Encümenin yetkisi dışında kalan aktarmaları yapmak.

j) İl Özel İdaresi personelini atamak.

k) İl Özel İdaresi, bağlı kuruluşlarını ve işletmelerini denetlemek.

l) Şartsız bağışları kabul etmek.

m) İl halkının huzur, esenlik, sağlık ve mutluluğu için gereken önlemleri almak.

n) Bütçede yoksul ve muhtaçlar için ayrılan ödeneği kullanmak.

o) Kanunlarla İl Özel İdaresine verilen ve İl Genel Meclisi veya İl Encümeni kararını gerektirmeyen görevleri yapmak ve yetkileri kullanmak (Md. 30).

\section{YERELLEŞME}

Geleneksel anlamda yerelleşme kavramı, Fransız yönetim biçimi anlayışı ekseninde "devletin içinde, yukarıdan aşağıya bir yetki aktarımı" süreci olarak literatürde kendine yer bulurken; çağın küreselleşme devrinde ise "merkezden taşra örgütüne yetki devri", "taşra örgütünden yerel yönetimlere yetki devri", "yetkinin her kademede bir alta devri" ve "yetkilerin topluma-özel sektöre devri" anlamlarını birlikte içeren bir tanımlamaya kavuşmuştur (Özel, 2007:58).

Bir başka ifadeyle yeni yüzyılın devlet anlayışına damga vuran adem-i merkeziyetçilik, katılımcılık, özerklik ve çoğulculuk kavramlarını bir bütün olarak ifade eden 'yerelleşme', dünya genelindeki 
uluslararası ve ulusal çevrelerde etkinliğini koruyan, üzerinde durulan ve kabul gören bir kavram olarak karşımıza çıkmaktadır. Küreselleşmeyle birlikte ulus-devletin hak ve yetkilerine sadece uluslar üstü kuruluşlar değil, merkezi yönetim dıșındaki kuruluşlar da göz dikmiștir. Ulus-devletin görevlerinin bir bölümü uluslar üstü kurumlara aktarllırken, bir bölümü de yerel yönetimlere devredilmiştir (Akbulut ve Göküş, 2017: 81).

\subsection{Yerelleşmenin Etkileri}

Yerel yönetimlerin yetkilerinin artırılmasıyla insan hakları, demokrasinin ve toplumsal yapının güçlenmesinde yerelleşmenin etkileri gözlenmektedir. Global bir değer olarak kabul edilen yerelleşmenin siyasal gücün tek elde toplanmasını önleyeceğini ve böylece yerel demokrasiyi güçlendirecek etkilere sahip olacaktır. Yerelleşme, yerel demokrasiyi güçlendirmek için çok önemli bir etkiye sahiptir. Yerelleşme bir yandan demokrasinin gelişmesini katkı sağlayacak olan halkın yönetime katılmasını sağlayacak etkiye sahipken diğer taraftan da yerel tiranlığı ve despotizmi de ortaya çıkarabilecek etkileri vardır (Bildirici: 2010:42-43). Yerelleşmeyle birlikte yerel kuruluşların işi benimsemesi, işin yöreye has özelliklerinin yakından tanınması, mal ve hizmetlerin zamanında gerçekleştirilmesi, planlama kolaylıkları, esneklik ve bireylerin etkili katılımı sağlanabilir (Akbulut, 2016:15).

\subsection{Yerelleşme Politikaları}

Yerelleşme, küreselleşmenin özünde taşıdığı tekdüzene ve merkeziyetçi yapının yeniden üreterek ve birbirine eklemleyerek küreselleşmenin daha yaygın bir hal almasını sağlamaktadır. Neo liberal yaklaşımlar, kamunun hizmet sunumundaki rolünü azaltma yönünde tavır sergilerken, kamu yönetiminin yeniden yapılandırılmasında özel sektör uygulamalarından yararlanılması yönünde gelişim göstermiştir. Bu durum kamusal üretimin yerine özel sektör üretiminin geçmesine, hizmet sunumunda kamu-özel sektör ortaklığının ön plana çıkması ile sonuçlanmıștır (Kerman, vd, 2008: 128-130 Bu oluşum zarfında yerel yönetimlere tanımlanan görev ve fonksiyonlarda değişiklikler meydana gelmiștir. Yerel halkı müșteri olarak gören ve isteklerine artan oranda bir vurgu sağlayan hizmet üretimi çerçevesinde, yerel yönetimler doğrudan hizmeti sağlayan kuruluşlar olmasından öte, hizmetin denetimine ve sunumuna yetki veren kurulușlar düzeyine ulașmasına imkan sağlamıștır (Gökbayrak, 2003:31-33).

\section{5302 SAYILI YASANIN YERELLEŞME BAĞLAMINDA DEĞERLENDİRİLMESİ}

5302 Sayılı İl Özel İdaresi Kanunu'nun 6. maddesinde yer alan “İl Özel İdaresi hizmetleri, vatandaşlara en yakın yerlerde ve en uygun yöntemlerle sunulur", ibaresi Avrupa Yerel Yönetimler Özerklik Şartı'nın 4. maddesinin 3. bendinde yer alan "Kamu sorumlulukları genellikle ve tercihen vatandaşa en yakın olan makamlar tarafından kullanılacaktır" hükmüyle örtüşmektedir (Demirel, 2014: 180). Uygulama da olan 5302 sayılı İl Özel İdare Kanununda; vali İl Genel Meclis başkanı olmaktan çıkarılmıștır. İl Genel Meclisi kararlarının vali onayı ile yürürlüğe girmesi uygulamasına son verilmiștir. İl Özel İdare bütçesi İçişleri Bakanlığı onayıyla değil, İl Genel Meclisi kararıyla yürürlüğe girmesi hükme bağlanmıștır. İl Özel İdaresinin İl Genel Meclisi kararıyla uluslararası teșekkül ve organizasyonlara üye olabilmesine olanak tanınmıștır (Akbulut ve Göküş, 2016: 78). Yerelleşme açısından olumlu bir gelişme kabul edilen bu değişiklikler valinin merkezi vesayeti azaltılmış olmasına rağmen alınan kararlara karşı idari yargı yolunun açık olması, valilerin diğer merkezi ve yerel yönetimler üzerindeki ağırlığını devam ettirmektedir (Balkanlığlu, 2013:1). 5302 Sayılı Yasa kapsamında gerçekleștirilen önemi değişikliklerden biri olarak kabul gören kesinleșen İl Genel Meclisi karar özetleri toplantıyı izleyen en geç yedi gün içinde çeşitli yollarla halka duyurulması Avrupa Yerel Yönetimler Özerklik Şartı'nın hizmetlerde yerindelik kontrolünün yerel meclislere ait olmasına ilişkin ilgili temel ilkeleriyle bu haliyle uyumlu İl Özel İdarelerinin yerelleşmesi açısından önem arz etmektedir (Toprak, 2012:15). 5302 Sayılı Kanun'un 45. Maddesinde "Vali tarafından hazırlanan bütçe tasarısı Eylül ayı basında İl Encümenine sunulur. Encümen bütçeyi inceleyerek görüşü ile beraber Kasım ayının birinci gününden önce İl Genel Meclisine sunar. İl Genel Meclisi bütçe tasarısını yılbaşından önce aynen yada değiștirerek kabul eder." hükmü getirilmiş ve İl Özel İdaresinin seçilmiş organını bütçenin kabulünde yeterli görmesi demokratik bir karar olan seçilmişlere önem veren bir tercih olduğunu açıkça belli etmiş ve bu kararla birlikte İl Özel İdarelerinde özerkliğin artırıldığı ve üzerindeki vesayetin bir nebze olsun azaldığı söylentileri yerelleşme açısından önemli bir gelişme olarak yerini almıştır (Uçar, 2011: 618). 5302 sayılı İl Özel İdaresi Kanunu İl Genel Meclisine İl Encümeninin başında bulunan valiyi denetleme yetkisi vermektedir. Kanunun 18.Maddesine göre; "Vali, mart ayı toplantısında bir önceki yıla ait faaliyet raporunu meclise sunar. Faaliyet raporundaki açıklamalar, meclis üye tam sayısının dörtte üç çoğunluğuyla yeterli görülmezse, yetersizlik kararıyla 
görüşmeleri kapsayan tutanak, meclis başkanı tarafından gereği yapılmak üzere İçişleri Bakanlığına gönderilir" Bu değişiklik valilerin İl Özel İdaresi üzerindeki tasarruf haklarını büyük ölçüde azaltmış ve İl Özel İdaresinin karar organı İl Genel Meclisinin etkinliği artırılmıștır(Tan ve Belli, 2013:266). Yeni Yasa İl Özel İdaresine verdiği geniş görev ve sorumlulukların yanında önemli yetki ve imtiyazlar da vermektedir. Kanunun "İl Özel İdaresinin yetkileri ve imtiyazları" başlıklı 7. maddesinde; İl Özel İdareleri, merkezin izni ve onayı olmadan, her türlü faaliyette bulunabilecek, gerçek ve tüzel kişilerin faaliyetleri için izin ve ruhsatları verebilecek ve onları denetleyebilecek, yönetmelik çıkarabilecek, emir verebilecek, yasaklar koyup bunları uygulayabilecek, çeşitli cezalar verebilecek, taşınır ve taşınmaz malları alabilecek, bunları satabilecek, kiralayabilecek veya kiraya verilebilecek, takas edebilecek, bunlar üzerinde sınırlı aynî hak tesis edebilecek, borç alabilecektir. İl Özel İdaresinin doğrudan kendi organlarının kararıyla kullanabilecekleri bu yetkiler yerelleşme açısından önem teşkil etmektedir (Akbulut, 2016:79.

\section{SONUÇ}

Türkiye'de, 1980 sonrası dönemde, tüm dünyayı etkisi altına alan küreselleşme süreci ve bu sürecin getirmiş olduğu yeni ekonomik düzen anlayıșı, kamu yönetimini ve onun ayrılmaz parçası olan yerelleşme politikalarını yakından etkilemiştir. Bu etkileşim, Avrupa Birliği'ne uyum sürecini yaşayan Türkiye için değiştirilmesi ve düzenlenmesi zorunlu olan yerelleşme politikalarını gündeme getirmiştir Yaşanan bu küresel değişim ve yenilikler ulusal kalkınma politikalarında, merkezi idarenin öncü role sahip olduğu tümden gelim yerine yerel aktörlerin daha etkin rol üstlendiği tümevarım yönteminin kullanılmasını gerekli kılmıștır. Avrupa Yerel Yönetimler Özerklik Şartı ilkeleri ekseninde Avrupa Birliği'ne uyum politikaları kıskacında yerelleşme reformları adı altında 5302 sayılı İl Özel İdaresi Kanunu, İl Özel İdaresi teșkilatının ișleyiși, yeni birimlerin kurulması, kaldırılması veya birleştirilmesi konusunda İl Genel Meclisine yetki vererek, bu konuda oldukça geniş esneklik sağlamaya çalışmıştır. Nitekim, 5302 sayılı İl Özel İdaresi Kanunu İl Genel Meclisine İl Encümeninin başında bulunan valiyi denetleme yetkisi vermektedir. Bu değişiklik valilerin İl Özel İdaresi üzerindeki tasarruf haklarını büyük ölçüde azaltmıș ve İl Özel İdaresinin karar organı İl Genel Meclisinin etkinliği artırılmıștır. 5302 sayılı Yasayla yapılan değișiklikle İl Özel İdaresi hizmetlerini vatandaşlara en yakın yerlerde ve en uygun yöntemlerle sunulması ve İl Genel Meclisi karar özetleri en geç yedi gün içinde çeşitli yollarla halka duyurulması ve İl Özel İdaresinin İl Genel Meclisi kararıyla uluslararası teşekkül ve organizasyonlara üye olabilmesine olanak tanınmış ve ayrıca merkezin izni ve onayı olmadan gerçek ve tüzel kişilerin faaliyetleri için İl Özel İdaresinin doğrudan kendi organlarının kararıyla kullanabilecekleri bazı yetkiler yerelleşme açısından önem teşkil unsurlar olarak yerini almıștır.

\section{KAYNAKÇA}

Akarçay, P. (2009). " Cumhuriyet'ten Günümüze Trakya'da Bölgesel Kalkınma Politikaları ve Bölge Kalkınma Ajansı”, Yayınlanmamış Yüksek Lisans Tezi, Trakya Üniversitesi / Sosyal Bilimler Enstitüsü, Edirne.

Akbulut, MUF. (2016). "Küreselleşme ve Yerelleşme Sürecinde Bölgesel Kalkınma Ajansları", Yayınlanmamış Yüksek Lisans Tezi, Selçuk Üniversitesi/ Sosyal Bilimler Enstitüsü, Konya.

Akbulut, MUF. \& Göküș, M. (2017). "Küreselleşme ve Yerelleşme Sürecinde Bölgesel Kalkınma Ajansları", Selçuk Üniversitesi Sosyal Bilimler Meslek Yüksekokulu Dergisi, 20(1): 79-88.

Balkanlığlu, İ. (2013). "Yeni Kamu Yönetimi Anlayışında Kalkınma Ajanslarının Yeri ve Valilerin Bu Yapılanmadaki Rolü Analizi" (Ed. Mustafa Ökmen, Güven Şeker, Fatih Yaman), KüreselleşmeYerelleşme Sarmalında Kalkınma Ajansları, ss.1-4 Orion Kitapevi, Ankara.

Bayrakçı, E. (2011). Yerel Yönetimler, Çizgi Yayınevi, Konya.

Bildirici, S.S. (2010). Dünden Bugüne Küreselleşme Yerelleşme ve Türkiye, Küreselleşme, Yeni Dünya Düzeni ve Yerelleşme İlişskisi, Gazi Kitapevi, Ankara,

Çetin, S. (2012). "Yerel Yönetim Birimi Olarak Türkiye'de İl Özel İdareleri”, Dumlupınar Üniversitesi Sosyal Bilimler Dergisi, (25): 249-258.

Dal, S. (2016). "İL Özel İdarelerinin Mevcut Durumu, Sorunları ve Geleceği Üzerine Bir Uygulama ", Yayınlanmamış Yüksek Lisans Tezi, Balıkesir Üniversitesi/ Sosyal Bilimler Enstitüsü, Balıkesir.

Demirel, S. (2014). "Yeni Yönetimin Ana Unsurları: Yerelleşme, Demokratikleşme ve İl Özel İdaresi”, Muş Alparslan Üniversitesi Sosyal Bilimler Dergisi, 2(2):174-187. 
Genç, Y. \& Barış, İ. (2015). "Sosyal Hizmetlerin Yeniden Yapılandırılmasında Yerinden Yönetimin İşlevselliği", The Journal of Academic Social Science Studies Dergisi, (32):95-117.

Gökbayrak, Şenay (2003). "Belediyelerce Sunulan Kentsel Hizmetlerin Özelleştirilmesi Çerçevesinde Taşeronluk ve Çalışma İlișkileri Üzerine Etkileri”, Mesleki Sağlık ve Güvenlik Dergisi, 4(16), 30-37.

Günal, A.; Atvur, S. \& Dernek, K.O. (2014). “6360 Sayılı Yasanın Yerelleşme Bağlamında Değerlendirilmesi", Süleyman Demirel Üniversitesi İktisadi ve İdari Bilimler Fakültesi Dergisi, 19(3): 55-70.

Kerman, U.; Altan, Y. \& Aktel, M. (2008). “Dönüșen Devlette Yerelleșme Politikaları: Kalkınma Planları Üzerinde Bir Analiz", Amme İdaresi Dergisi, 41(3): 125-152.

Koçak, S.Y. \& Kavsara, V. (2012). “ 5302 Sayılı Kanun Sonrasında İl Özel İdarelerinde Yaşanan Sorunlar ve Çözüm Önerileri”, Yönetim Bilimleri Dergisi, 10(20): 61-92.

Özel, Mehmet (2007). "Bir Yerelleşme Biçimi Olarak Özelleştirme, Rekabetle İlişkisi ve Yerel Yönetimlerde Uygulamaları", Yönetim ve Ekonomi Araştırmaları Dergisi, (8): 57-81.

Resmi Gazete, "5302 İl Özel İdaresi Kanunu, http://www.resmigazete.gov.tr/eskiler/2005/03/20050304-1.htm, (Erişim Tarihi: 25.11.2017).

Sobacı, M.Z. (2005). " Yeniden Yapılanma Sürecinde İl Özel İdarelerinin Dünü, Bugünü Ve Geleceği Üzerine Değerlendirmeler", Çağdaş Yerel Yönetimler Dergisi, 14(4): 31-50.

Tan, M. \& Belli, A. (2013). "Yerel Kalkınma, Yerel Demokrasi ve Katılım: Kahramanmaraş Örneği”(Ed., Mustafa Ökmen, Uluç Cağatay, Ayșe Berna Görmez), Küreselleșme-Yerelleșme Dikotomisinde, Yerel ve Bölgesel Kalkınma- Kamu Yönetimi Perspektifi, ss.251-284, Orion Kitapevi, Ankara.

Toprak, Z. (2012). “Türkiye'de Yerel Yönetimler-Yapılanma Merkez -Yerel Yönetim İlișkileri”, ss.1-28. http://kisi.deu.edu.tr/zerrin.toprak/TURKIYE'DE\%20YEREL\%20YONETIMLER\%20YAPILANMA.pd , (Erișim Tarihi, 28.10.2017).

Uçar, A. (2011). " İl Özel İdarelerinde Demokratik Katılım ve Yönetişim Uygulamaları", Celal Bayar Üniversitesi Sosyal Bilimler Dergisi, 9(2): 613-629.

Yılmaz, A. (2010). “Kalkınma Ajansları ve Yerel Yönetișim”, Türk İdare Dergisi, (466): 175-195. 